\title{
Análisis de estrategias de brotación de familias de polinización abierta de Prosopis alba Grisebach de Argentina
}

Frassoni, J. E., Giannini Kurina, F., López Lauenstein, D. y Joseau, M. J.

DOI 10.31047/1668.298x.v38.n2.28610

\begin{abstract}
RESUMEN
El objetivo del trabajo fue analizar las estrategias de brotación de familias de polinización abierta de Prosopis alba Grisebach en Argentina. Se seleccionaron 88 familias de interés en un ensayo de progenies ubicado en la provincia de Santiago del Estero que fueron clasificadas 16 orígenes geográficoclimáticos (OGC) contrastantes. Se realizaron 16 observaciones fenológicas en los individuos marcados entre el 21 de agosto y el 8 de octubre del 2016; se estableció el momento de inicio de brotación y el porcentaje de brotación en cada fecha. Las estrategias de brotación fueron evaluadas a través de la construcción de un índice de brotación para cada origen geográfico-climático, el modelado del porcentaje de brotación en función del tiempo, y el análisis de las velocidades medias de crecimiento de los brotes por origen geográficoclimático. Se evidencia que existen cuatro estrategias de brotación que surgen de la combinación de tres grupos de brotación y dos grupos de velocidad de brotación, siendo las variables climáticas de temperatura media anual y temperatura del mes más frío las que diferencian estos grupos.
\end{abstract}

Palabras clave: orígenes geográfico-climáticos, fenología, índice de brotación, algarrobo blanco

Frassoni, J. E., Giannini Kurina, F., López Lauenstein, D. and Joseau, M. J., 2021. Sprouting strategies analysis of open-pollinated families of Prosopis alba Grisebach in Argentina. Agriscientia 38 (2): 27-40

\section{SUMMARY}

The aim of this work was to analyze the sprouting strategies of open-pollinated families of Prosopis alba Grisebach in Argentina. In a progeny trial located in the province of Santiago del Estero, 88 families of interest were selected and classified into 16 groups according to the geographical location or climatic behavior of their origin sites. Each individual was characterized according to 16 phenological observations between August 21 and October 8 in 2016. From these measurements sprouting start date and sprouting percentage of each 
geographical and climatic origin were established. The sprouting strategies were evaluated through the design of a sprouting index for each geographical and climatic origin, through the modeling of the sprouting percentage as a function of time, and the analysis of the mean sprouting rate by geographical and climatic origins. Results show four sprouting strategies that arise from the combination of three sprouting groups and two sprouting speed groups, the climatic variables of mean annual temperature and temperature of the coldest month being the ones that differentiate these groups.

Key words: climatic geographic origins, phenology, sprouting index, white algarrobo

Frassoni, J. E. (ORCID: 0000-0002-7014-5104) y Joseau, M. J. (ORCID: 0000-0002-7871-9782): Universidad Nacional de Córdoba, Cátedra de Silvicultura, Facultad de Ciencias Agropecuarias, Argentina. Giannini Kurina, F. (ORCID: 0000-0001-6763-7792): Consejo Nacional de Investigaciones Científicas y Técnicas (CONICET) Universidad Nacional de Córdoba, Argentina. López Lauenstein, D. (ORCID: 00000003-1464-2699): Instituto Nacional de Tecnología Agropecuaria (INTA), Instituto de Fisiología y Recursos Genéticos Vegetales, Centro de Investigaciones Agropecuarias, Córdoba, Argentina. Correspondencia a: javierfrassoni@agro.unc.edu.ar

\section{INTRODUCCIÓN}

Prosopis alba Griseb. (algarrobo blanco) es un árbol nativo pionero de la familia de las Fabáceas de las zonas áridas, semiáridas y subhúmedas de las Ilanuras subtropicales de Argentina, Uruguay, Paraguay, sur de Bolivia y norte de Chile y Perú (Galera, 2000; Verzino y Joseau, 2005; Ledesma et al., 2008; Karlin et al., 2013; Fontana et al., 2020). En Argentina es muy abundante en la zona centro y norte del país, en las provincias fitogeográficas del Chaco semiárido y subhúmedo, Espinal y del Monte (Ledesma et al., 2008; Navall et al., 2015).

P. alba, leñosa multipropósito, es una de las especies forestales nativas más cultivada en Argentina (9000 ha) como fuente de madera para aserrío (Salto et al., 2019; López Lauenstein et al., 2021), aunque más del $80 \%$ de la madera utilizada proviene de los bosques nativos de la región chaqueña, principalmente de las provincias de Chaco y Formosa (Navall et al., 2015). Su creciente utilización para leña, forraje y alimentos hace que este recurso sea explotado sin tener en cuenta los principios básicos de un aprovechamiento racional y sostenido (de Galindez et al., 2005). Su madera es valiosa por su excelente veteado y estabilidad dimensional que permite el procesamiento sin necesidad de secado (Coronel de Renolfi et al., 2012), se la usa también para carpintería de obra, parquet y revestimientos (de Galindez et al., 2005).

La drástica disminución de los bosques de $P$. alba ha promovido el interés en usar a la especie en plantaciones, con el propósito de renovar el recurso productivo y de recuperar ecosistemas degradados. Produce semilla de buen poder germinativo que se mantiene por mucho tiempo, por lo que se adapta sin inconveniente al cultivo y sus recursos genéticos son de relativa fácil conservación ex-situ (Verzino y Joseau 2005; Joseau et al., 2013). Por su bajo requerimiento en fertilidad de suelos tiene cierta tolerancia a suelos salinos y alta adaptación a condiciones extremas de temperatura, por lo que no compite con otras actividades productivas (Navall et al., 2015). Desde hace 20 años está siendo promocionada para su uso en plantaciones comerciales a través del subsidio nacional que otorga la Ley № 25080. La mayoría de estas plantaciones no han tenido manejo silvícola y se desconoce el material genético (semillas) que le dio origen (Salto et al., 2019), aunque se ha avanzado en los últimos diez años en la obtención de material mejorado (Verga et al., 2009).

Otro factor importante a tener en cuenta para la conservación y la domesticación de los recursos genéticos es el cambio climático ocurrido en las últimas décadas, tal como lo informa el Grupo Intergubernamental de Expertos sobre el Cambio Climático (Pachauri y Reisinger, 2007). Recientemente, el calentamiento de las altas latitudes del hemisferio sur y los cambios consecuentemente producidos en el régimen 
hídrico han afectado la diversidad específica, genética y ecológica en una forma cuali-cuantitativa aún no mensurada en Argentina.

Las especies se adaptan a variaciones espaciales o temporales utilizando distintas estrategias (Levins, 2020): básicamente la diferenciación, en la que se altera la frecuencia de las variantes genéticas (génicas y genotípicas), o la plasticidad fenotípica, por la que un mismo acervo genético se aclimata a un amplio rango de ambientes. Los estudios genecológicos son apropiados para investigar la variabilidad genética de las especies en función de la variación ambiental (Joyce et al., 2001). Además de estudios genecológicos es importante realizar estudios fenológicos y ecofisiológicos para conocer el comportamiento de las especies a diferentes ambientes. En este marco, los ensayos de orígenes y progenies de genotipos selectos pueden brindar el conocimiento de los patrones de variación genética y probar su desempeño y adecuación a las condiciones ambientales de los sitios de destino (López et al., 2001).

Los registros fenológicos constituyen un método efectivo para conocer la relación entre la variabilidad climática y el comportamiento de las plantas, es decir, los posibles efectos que en ellas puedan provocar las modificaciones actuales y futuras del clima (Spano et al., 1999). Parizek et al. (2000) sostienen que los estudios fenológicos aportan información relevante para la interpretación de los procesos de especiación involucrados y para planteos de manejo del recurso con fines productivos. El crecimiento potencial, la tolerancia a heladas y el ritmo de crecimiento son las variables compuestas más frecuentemente utilizadas para analizar el desempeño de las especies ante nuevas condiciones (Dietrichson, 1964; Rehfeldt, 1984).

Existen estudios en el género Prosopis que describen el comportamiento de las especies en el proceso de brotación. Ocampo y Orquin (1989) lo estudiaron para $P$. flexuosa en San Luis; Carranza et al. (2000) para P. chilensis en Córdoba; Parizek et al.(2000) para $P$. chilensis y P. flexuosa en Córdoba, mientras que Debandi et al. (2020) lo hicieron para P. flexuosa en Mendoza. Otros autores como Ocampo y Orquin (1989); Murphy et al. (1999); Garau et al. (2000); Menzel (2003) y Carnelos et al. (2019) estudiaron las relaciones existentes entre la ocurrencia de las fenofases de brotación y las variables climáticas, pero en ningún caso estas descripciones se realizaron para $P$. alba. En cuanto al crecimiento de los brotes, Sharifi et al. (1983) realizaron una descripción de $P$. glandulosa en California. Asimismo, Córdoba y Verga (2008), estudiaron el ritmo de floración en un enjambre híbrido entre $P$. chilensis y $P$. flexuosa en el oeste de la provincia de Córdoba, para comprender el sistema de apareamiento.

En estudios genecológicos de P. chilensis realizados por Carranza et al. (2000) sobre 6 poblaciones de Chile y 17 de Argentina (cosechadas en las provincias de Córdoba, La Rioja y Catamarca), se llevó a cabo un ensayo de procedencias en la Estación Forestal de INTA Villa Dolores. En este ensayo se estudió la variación adaptativa a través del índice de brotación y longitud del primer brote al cuarto año de crecimiento y se confirmó la presencia de un patrón de variación adaptativa de la especie en función de la latitud, longitud y altitud.

Estainformación, sinembargo, no está disponible para $P$. alba, por lo que estudios de este tipo son necesarios para conocer el comportamiento de diferentes orígenes que posibiliten la selección de material apto para distintos sitios forestales. El objetivo del presente trabajo fue analizar las estrategias de brotación de familias de polinización abierta de P. alba Grisebach en Argentina.

\section{MATERIALES Y MÉTODOS}

Se utilizó un ensayo de progenies de $P$. alba de 8 años ubicado en la provincia de Santiago del Estero ( $\left.27^{\circ} 56^{\prime} 45,1^{\prime \prime} \mathrm{S}, 64^{\circ} 13^{\prime} 12,5^{\prime \prime} \mathrm{O}\right)$ en un sitio con una altitud de 174 m s.n.m., precipitación anual promedio de $578 \mathrm{~mm}$, temperatura $\left(\mathrm{T}^{\circ}\right)$ promedio anual de $20,7^{\circ} \mathrm{C}$ y temperatura promedio máxima / mínima de $35,2^{\circ} \mathrm{C} / 5,1^{\circ} \mathrm{C}$ respectivamente (Salto, 2011), suelo Haplustol árido de textura francoarenosa que tiene como principal limitación la baja retención de humedad (Secretaria de Agricultura, Ganadería y Pesca [SAGyP] e INTA, 2013).

Al momento del estudio (año 2016), el ensayo estaba formado por 3671 árboles de 202 progenies (familias) de $P$. alba de poblaciones originarias de las provincias de Santiago del Estero, Chaco, Salta, Formosa y Entre Ríos. El ensayo fue instalado con un diseño de tres bloques completamente al azar en parcelas de árbol único no contiguas con un número variable de repeticiones por familia (entre 15 y 21 individuos) y un borde perimetral simple. La distancia de plantación fue de $4 \times 4 \mathrm{~m}$ en los tres bloques (625 árboles por hectárea) sin que les hubieran realizado ningún tratamiento intermedio de poda o raleo.

Del total del ensayo, se seleccionaron 88 familias de polinización abierta de $P$. alba por su contrastante ubicación geográfica o 
comportamiento climático de los sitios de origen. Las 88 familias se clasificaron en 16 orígenes geográfico-climáticos, referidos: 4 a condiciones climáticas, 11 al lugar de origen y 1 a elevación. Los orígenes fueron los cuatro establecidos por Verga et al. (2009) y López Lauenstein et al. (2016) (Chaqueño, Chaqueño Sur, Salteño Norte, Salteño Centro) y los 7 establecidos por el grupo de trabajo Bermejo-Salta, Formosa Norte, Santiago Sur, Entre Ríos, Santiago Norte, Santiago Este y Santiago
Oeste, como ilustra la Figura 1.

La Tabla 1 caracteriza los 16 orígenes geográficoclimáticos utilizando 7 variables climáticas de interés ( $T^{\circ}$ media anual (TMA), $T^{\circ}$ mínima media del mes más frío (TMF), $T^{\circ}$ máxima media del mes más caliente (TMC), elevación, precipitación, longitud y latitud).

Las estrategias de brotación fueron analizadas a través del índice de brotación construido para cada origen geográfico-climático, el modelado

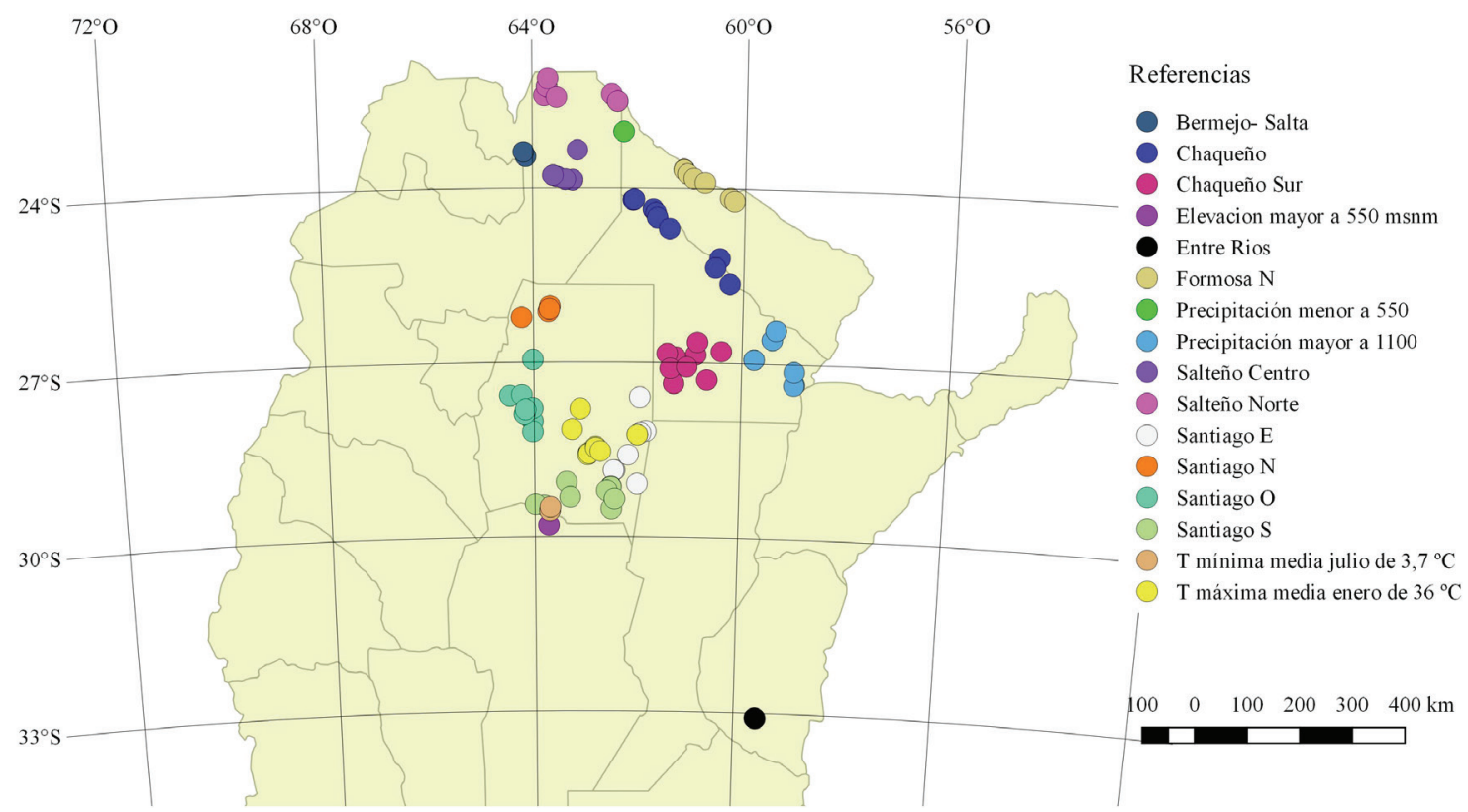

Figura 1. Distribución de los 16 orígenes geográfico-climáticos seleccionados correspondientes a las 88 familias del ensayo

Tabla 1. Caracterización geográfica- climática de los 16 orígenes geográfico-climáticos seleccionados

\begin{tabular}{|c|c|c|c|c|c|c|c|}
\hline $\begin{array}{l}\text { Origen y cantidad de individuos } \\
\text { colectados }\end{array}$ & $\begin{array}{l}\text { TMA } \\
\left({ }^{\circ} \mathrm{C}\right)\end{array}$ & $\begin{array}{c}\mathrm{TMF}^{*} \\
\left({ }^{\circ} \mathrm{C}\right)\end{array}$ & $\begin{array}{c}\mathrm{TMC}^{*} \\
\left({ }^{\circ} \mathrm{C}\right)\end{array}$ & $\begin{array}{l}\text { Elevación } \\
\text { (m.s.n.m) }\end{array}$ & $\begin{array}{l}\text { Precipitación } \\
(\mathrm{mm})\end{array}$ & $\begin{array}{l}\text { Latitud } \\
\text { (grados) }\end{array}$ & $\begin{array}{l}\text { Longitud } \\
\text { (grados) }\end{array}$ \\
\hline Bermejo- Salta (6) & 22,82 & 9,30 & 34,42 & 259 & 767 & $-23,680$ & $-63,690$ \\
\hline Chaqueño (10) & 22,46 & 9,42 & 34,63 & 147 & 798 & $-24,900$ & $-61,130$ \\
\hline Chaqueño Sur (10) & 21,72 & 8,37 & 35,19 & 100 & 943 & $-26,980$ & $-60,910$ \\
\hline Elevación mayor a 550 msnm (2) & 19,60 & 5,80 & 31,85 & 583 & 915 & $-26,020$ & $-63,730$ \\
\hline Entre Ríos (2) & 17,70 & 6,30 & 31,80 & 9 & 1027 & $-33,090$ & $-59,550$ \\
\hline Formosa N (7) & 22,96 & 10,20 & 34,73 & 156 & 670 & $-23,890$ & $-60,800$ \\
\hline Precipitación mayor a 1100 (6) & 21,50 & 9,78 & 33,62 & 69 & 1218 & $-26,960$ & $-59,250$ \\
\hline Precipitación menor a 550 (2) & 23,00 & 9,60 & 34,55 & 233 & 516 & $-22,760$ & $-62,350$ \\
\hline Salteño Centro (4) & 22,90 & 9,30 & 34,78 & 238 & 754 & $-23,820$ & $-63,450$ \\
\hline Salteño Norte (4) & 22,47 & 9,13 & 33,64 & 392 & 854 & $-22,490$ & $-63,270$ \\
\hline Santiago $E(8)$ & 20,89 & 6,80 & 35,70 & 95 & 793 & $-28,450$ & $-62,100$ \\
\hline Santiago N (4) & 21,38 & 7,15 & 34,13 & 265 & 669 & $-26,110$ & $-63,840$ \\
\hline Santiago O (9) & 20,74 & 5,42 & 35,14 & 178 & 592 & $-27,730$ & $-64,150$ \\
\hline Santiago S (11) & 19,40 & 4,96 & 33,72 & 247 & 752 & $-29,350$ & $-63,200$ \\
\hline T máxima media enero de $36^{\circ} \mathrm{C}(9)$ & 21,03 & 6,40 & 36,34 & 110 & 659 & $-28,370$ & $-62,840$ \\
\hline T mínima media julio de $3,7^{\circ} \mathrm{C}(2)$ & 17,80 & 3,37 & 31,63 & 556 & 762 & $-29,610$ & $-63,710$ \\
\hline
\end{tabular}

'TMA: T media anual, TMF: $T^{\circ}$ mínima media del mes más frío y TMC: $T^{\circ}$ máxima media del mes más caliente. 
del porcentaje de brotación en función del tiempo y el análisis de las velocidades medias de crecimiento de los brotes por origen geográficoclimático. Para sus cálculos se tomó al azar una muestra de 502 individuos pertenecientes a los tres bloques del ensayo (177 individuos del bloque I, 178 individuos del bloque II y 147 individuos del bloque III), todos los individuos tenían buena forma y estado sanitario. Se midió el diámetro a la altura de pecho (DAP) y altura total, a la vez que se realizaron 16 observaciones fenológicas en los individuos marcados entre el 21 de agosto y el 8 de octubre del 2016. A través de estas mediciones se establecieron: el momento de inicio de brotación siguiendo las consideraciones establecidas por Parizek et al. (2000) para yema brotada y el porcentaje de brotación (según Carranza et al., 2000) en las 16 fechas de observaciones.

Índice de brotación. Para inferir la velocidad de brotación de los orígenes geográfico-climáticos se elaboró el índice de brotación de P. alba para Santiago del Estero (IB), basado en el índice de brotación de Carranza et al. (2000) [Ec.1].

$$
\mathrm{IB}=\ln \left(\sum_{\mathrm{i}}^{\mathrm{k}} \mathrm{B}_{\mathrm{i}}\right) \text { [Ec.1] }
$$

donde $B_{i}$ es el porcentaje de brotación en la observación $i$ - ésima; $P_{j}$ es el número de días transcurridos desde el inicio de las observaciones hasta la observación $i$ - ésima y k es el número total de observaciones. En este índice, un individuo que presenta el $100 \%$ de brotación el primer día de observación presentará un valor de índice de brotación igual a 4,6; valores menores se corresponden a un retraso en el inicio de la brotación en el tiempo. Es de destacar que este índice está afectado por la duración del período entre que comenzaron las observaciones y el momento de brotación. Se realizó un ANAVA con el software estadístico Infostat (Di Rienzo et al., 2018) a partir de un modelo lineal mixto, considerando el factor de diseño bloque como efecto aleatorio y el factor origen geográfico-climático como efecto fijo. Se realizaron contrastes entre los orígenes geográfico-climáticos a partir de la prueba a posteriori DGC (Di Rienzo, Guzmán y Casanoves, 2002), identificando grupos de comportamiento respecto al índice de brotación (grupos de brotación [GB]). Los orígenes que formaron cada grupo de brotación fueron graficados en un mapa de la Argentina utilizando para esto el programa QGIS (QGIS Development Team, 2016). Se calculó la autocorrelación espacial del índice de brotación con índice de Moran. Se realizó un análisis de componentes principales (ACP) y un ANAVA de los grupos de brotación en función de las variables climáticas ( $\mathrm{T}^{\circ}$ media anual, $\mathrm{T}^{\circ}$ mínima media del mes más frío, $T^{\circ}$ máxima media del mes más caliente, elevación, precipitación, longitud y latitud) para identificar qué variables definían a los grupos formados.

Brotación en el tiempo. Se modeló el comportamiento del porcentaje de brotación por grupo de brotación en función del tiempo a partir de un modelo logístico [Ec.2].

$$
\left.\mathrm{B}(\mathrm{t})_{\mathrm{i}}=\frac{\alpha}{1+\mathrm{e}^{\frac{\left(-\left(\mathrm{t}-\left(\beta+\mathrm{u}_{\mathrm{i}}\right)\right.\right.}{\gamma+v_{\mathrm{i}}}}} \quad \text { [Ec. } 2\right]
$$

donde es el porcentaje de brotación (\%) para el grupo de brotación, mientras $\alpha, \beta$ y $\gamma$ son los parámetros que definen la función logística, $t$ es el número de días desde el comienzo de las observaciones, mientras que $u_{i}$ y $v_{i}$ son términos que modifican la ecuación logística media según el grupo de brotación.

Se consideró el efecto grupo de brotación como efecto aleatorio sobre los términos del modelo $\beta$ y $\gamma$, los cuales modifican la pendiente de la curva, de esta manera se construyó una curva de brotación para cada grupo, así como también una curva que representa el comportamiento medio de los grupos de brotación. Se identificaron los valores de $u_{i}$ y $v_{i}$ conocidos como BLUP (por sus siglas en inglés: best linear unbiased predictors) para cada grupo de brotación y se obtuvieron las ecuaciones que describen sus comportamientos.

Velocidad media de crecimiento de los brotes. Se seleccionaron, en cada origen geográficoclimático, los tres árboles de mayor diámetro, uno de diámetro intermedio y los tres de menor diámetro, todos diámetros registrados a altura de pecho (DAP). Se siguió la metodología de selección adoptada por Frassoni y Joseau (2019), sumando un total de 112 árboles (16 orígenes geográficoclimáticos por 7 árboles de cada origen). La Tabla 2 muestra las medias diferenciales $(p<0,05)$ de clases diamétricas establecidas y que se definen como material de este ensayo.

Se marcaron ocho brotes por árbol: dos brotes en orientación norte, dos en orientación sur, dos en

Tabla 2. Diámetro a la altura de pecho (DAP) por clase diamétrica

\begin{tabular}{lcc}
\hline Clases diamétricas & \multicolumn{2}{c}{ (DAP) } \\
$\mathrm{cm}$
\end{tabular}

Medias con una letra común no son significativamente diferentes $(p>0,05)$. 
orientación este y dos en orientación oeste (Figuras $2 a$ y $2 b$ ). Se realizaron entre una y tres mediciones según el momento de brotación. La variable registrada fue longitud del brote en centímetros en diferentes fechas de medición en un período de 43 días (desde el 26/08/2016 al 7/10/2016). Se determinó la velocidad media de crecimiento de los brotes para el período medido, dividiendo el crecimiento total alcanzado $(\mathrm{cm})$ al momento de finalizar el ensayo sobre la cantidad de días en la que ocurrió ese crecimiento.

Se efectuó un modelo lineal mixto con el software InfoStat (Di Rienzo et al., 2018), considerando como variable respuesta la velocidad media de crecimiento de los brotes en función del DAP y del origen geográfico-climático. Se consideró como efecto aleatorio a los factores del diseño experimental, orientación del brote y bloque. Se corrigió heterocedasticidad por origen y se realizaron contrastes entre los orígenes geográficoclimáticos a partir de la prueba a posteriori DGC, identificando grupos de comportamiento respecto a la velocidad media de crecimiento de los brotes. Los grupos resultantes fueron graficados en un mapa de la Argentina, utilizando para esto el software QGIS (QGIS Development Team, 2016). Se calculó la autocorrelación espacial de la velocidad media de crecimiento de los brotes con índice de Moran. Se realizó un ANAVA de los grupos de velocidad media de crecimiento de los brotes en función de las variables climáticas $\left(T^{\circ}\right.$ media anual, $T^{\circ}$ mínima media del mes más frío, $T^{\circ}$ máxima media del mes más caliente, elevación, precipitación, longitud y latitud) para identificar qué variables definían a los grupos formados.

\section{RESULTADOSY DISCUSIÓN}

Índice de brotación (IB). El índice de brotación de $P$. alba en Santiago del Estero para los 16 orígenes geográfico-climáticos varió de 1,70 a 3,19 mostrando diferencias significativas $(p<0,05)$ y dio lugar a la formación de tres grupos de brotación (Tabla 3), destacándose el grupo de brotación "temprana" con mayor $(p<0,05)$ valor de índice de brotación $(3,19)$, siendo el origen geográficoclimático seleccionado por crecer en sitios con temperaturas mínimas menores a $3,7^{\circ} \mathrm{C}$ parte de este grupo. La Tabla 3 muestra los tres grupos de brotación formados según el índice de brotación y la Figura 3 muestra la duración de las fechas de brotación de cada grupo. La nomenclatura utilizada para los grupos de brotación responde a la duración de la fase de brotación, siendo el de brotación temprana el grupo que más rápido culmina dicha fase.

Varios autores registraron distintos momentos de brotación en especies del género Prosopis para Argentina. Parizek et al. (2000) observaron, estudiando un bosque nativo ubicado en la localidad de Chancaní, provincia de Córdoba (Argentina), que la fenofase de yema hinchada se presentaba en un $75 \%$ de los árboles de $P$. flexuosa y en un $13 \%$ de los árboles en $P$. chilensis el 10 de septiembre. Al respecto, Ocampo y Orquin (1989) registraron en un bosque nativo de mayor latitud y localizado en Villa Mercedes

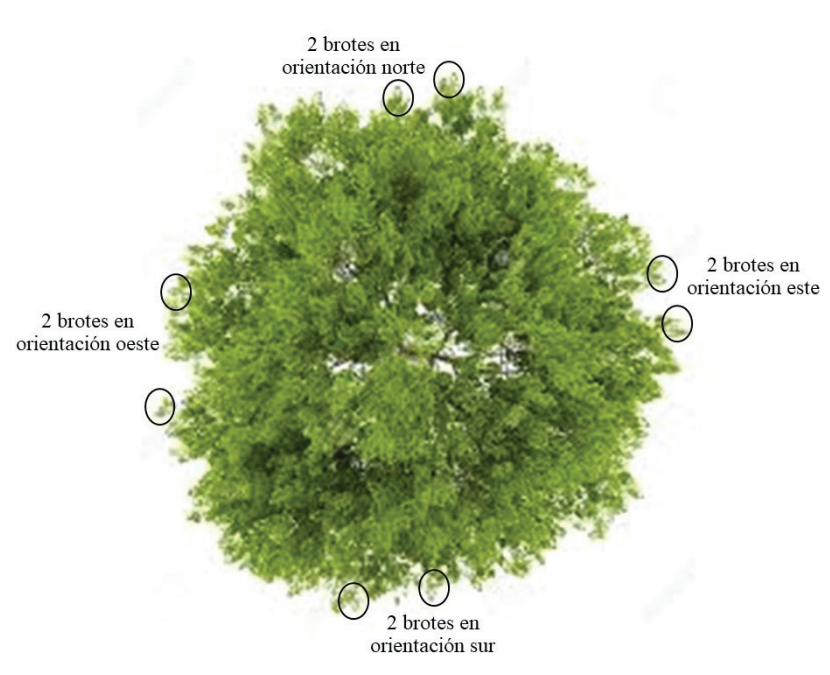

a)

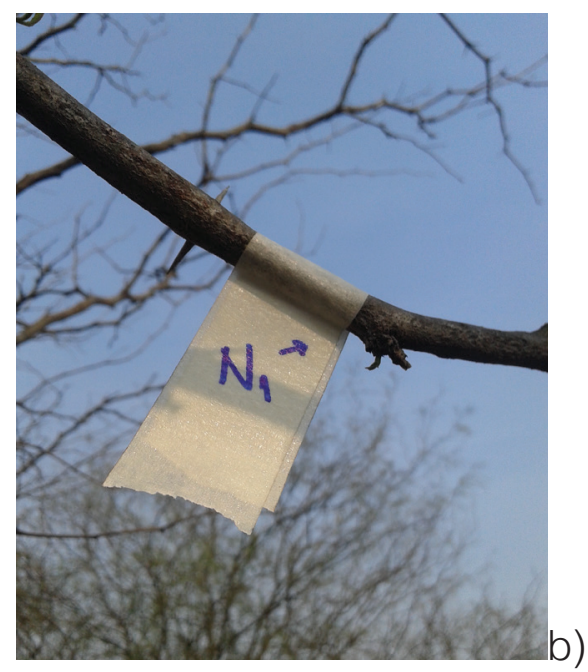

Figura 2. Detalles de la metodología de obtención de los datos de brotación: a) vista superior del árbol con ubicación de los brotes marcados y b) brote marcado en orientación norte 
Figura 3. Duración de la fase de brotación en días julianos por cada grupo de brotación formado. GBTE: grupo de brotación temprana, GBI: grupo de brotación intermedia y GBTA: grupo de brotación tardía

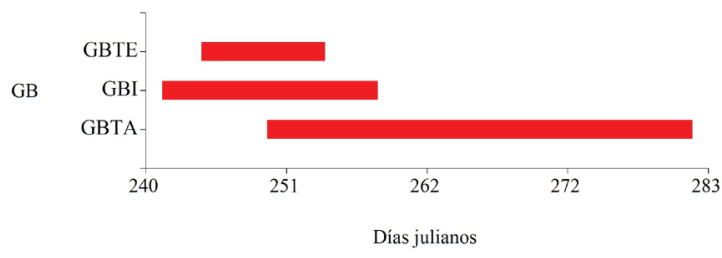

Tabla 3. Índice de brotación de Prosopis alba en Santiago del Estero por orígenes geográfico-climáticos

\begin{tabular}{|c|c|c|c|c|}
\hline $\begin{array}{l}\text { Orígenes geográfico- } \\
\text { climáticos }\end{array}$ & $\begin{array}{l}\text { Índice de } \\
\text { brotación }\end{array}$ & E.E. & & $\begin{array}{l}\text { Grupo de } \\
\text { brotación }\end{array}$ \\
\hline $\begin{array}{l}\text { T mínima media julio } \\
\text { de } 3,7^{\circ} \mathrm{C}\end{array}$ & 3,19 & 0,16 & A & $\begin{array}{c}\text { Temprana } \\
(1 / 9-9 / 9)\end{array}$ \\
\hline Santiago S & 2,86 & 0,14 & $\mathrm{~B}$ & \multirow{5}{*}{$\begin{array}{l}\text { Intermedia } \\
(29 / 8-13 / 9)\end{array}$} \\
\hline Santiago O & 2,79 & 0,15 & $\mathrm{~B}$ & \\
\hline $\begin{array}{l}\text { T máxima media } \\
\text { enero de } 36^{\circ} \mathrm{C}\end{array}$ & 2,67 & 0,15 & B & \\
\hline Entre Ríos & 2,51 & 0,17 & B & \\
\hline Santiago N & 2,48 & 0,15 & $\mathrm{~B}$ & \\
\hline Chaqueño & 2,20 & 0,16 & $C$ & \multirow{10}{*}{$\begin{array}{c}\text { Tardía } \\
(6 / 9-7 / 10)\end{array}$} \\
\hline \multirow{3}{*}{$\begin{array}{l}\text { Formosa N } \\
\text { Elevación mayor a } \\
550 \text { m.s.n.m. } \\
\text { Chaqueño Sur }\end{array}$} & 2,19 & 0,15 & C & \\
\hline & 2,12 & 0,19 & C & \\
\hline & 2,03 & 0,16 & C & \\
\hline \multirow{5}{*}{$\begin{array}{l}\text { Salteño Centro } \\
\text { Precipitación mayor a } \\
1100 \mathrm{~mm} \\
\text { Bermejo- Salta } \\
\text { Precipitación menor a } \\
550 \mathrm{~mm} \\
\text { Santiago E }\end{array}$} & 2,02 & 0,16 & C & \\
\hline & 1,99 & 0,16 & C & \\
\hline & 1,96 & 0,16 & C & \\
\hline & 1,95 & 0,17 & C & \\
\hline & 1,92 & 0,16 & C & \\
\hline Salteño Norte & 1,70 & 0,14 & C & \\
\hline
\end{tabular}

Medias con una letra común no son significativamente diferentes $(p>0,05)$

de la provincia San Luis, que la fecha en la que se cumple la fenofase de brotación en $P$. flexuosa tiene un inicio el día juliano 294 (21 de octubre) y un fin el día 311 ( 7 de noviembre); iguales registros obtuvieron para $P$. caldenia en esta fenofase. Debandi et al. (2020) registraron para dos reservas naturales de $P$. flexuosa en Mendoza (sitios ubicado a mayor longitud que los anteriores) que el crecimiento vegetativo comenzó los primeros días del mes de octubre (275 día juliano), pero el mayor porcentaje de individuos en el estadio de brotación lo encontraron a mediados de octubre (287 día juliano).
Las fechas de inicio de las brotaciones de cada grupo fueron: 01/09 para el grupo de brotación temprana, 29/08 para el grupo intermedia y 06/09 para el grupo de brotación tardía; mientras que las fechas finales de brotación fueron: 09/09, 13/09 y $7 / 10$ para los grupos de brotación temprana, intermedia y tardía respectivamente. En cuanto a la localización geográfica puede observarse que $P$. alba en Santiago del Estero presenta similitudes y diferencias con respecto a la brotación registrada en otras especies del mismo género localizadas en otras provincias. Puede observarse que $P$. alba en Santiago del Estero presenta su brotación en época similar a la registrada por Parizek et al. (2000) para bosque nativo de $P$. chilensis en Chancaní, Córdoba, localidad situada a $1^{\circ}$ de longitud de distancia de Santiago del Estero. Por otro lado, se adelanta a la brotación de bosque nativo de $P$. flexuosa y $P$. caldenia en San Luis registrada por Ocampo y Orquin (1989), inicios de brotación que se separan en el tiempo principalmente por estar ubicados a latitudes muy disímiles a los de Santiago del Estero.

Carnelos et al. (2019), quienes realizaron un seguimiento fenológico de 12 especies forestales ornamentales (nativas y exóticas) en la provincia de Buenos Aires en el 2016, reconocieron que en la mayoría de las especies se adelantó la fecha de brotación con respecto a registros históricos y que algunas de estas especies también redujeron la duración de la fase.

Para el presente estudio, se establecieron tres grupos de brotación con una duración de la fenofase de 9 días para el grupo de brotación temprana, 16 días para el grupo de brotación intermedia y de 32 días para el grupo de brotación tardía.

Se observa que los grupos de brotación formados mostraron una estructura espacial tal como se muestra en la Figura 4: el origen geográfico-climático con mayor valor de índice de brotación (el grupo de brotación temprana) se ubica en el límite sur de Santiago del Estero con Córdoba, los orígenes geográfico-climáticos con mediano valor de índice de brotación (grupo de brotación intermedia), en la región centro de la distribución, mientras que los orígenes con menor valor del índice (grupo de brotación tardía), lo hicieron en la región norte y este. Sin embargo, no hubo autocorrelación espacial del índice de brotación (índice de Moran= 0,02 $-p>0,05$ ).

Carranza et al. (2000) obtuvieron en el ensayo genecológico de 17 poblaciones de $P$. chilensis de Argentina y 6 de Chile, los mayores índices de brotación (mayor a 40) para todas las poblaciones de Chile y las poblaciones argentinas procedentes 


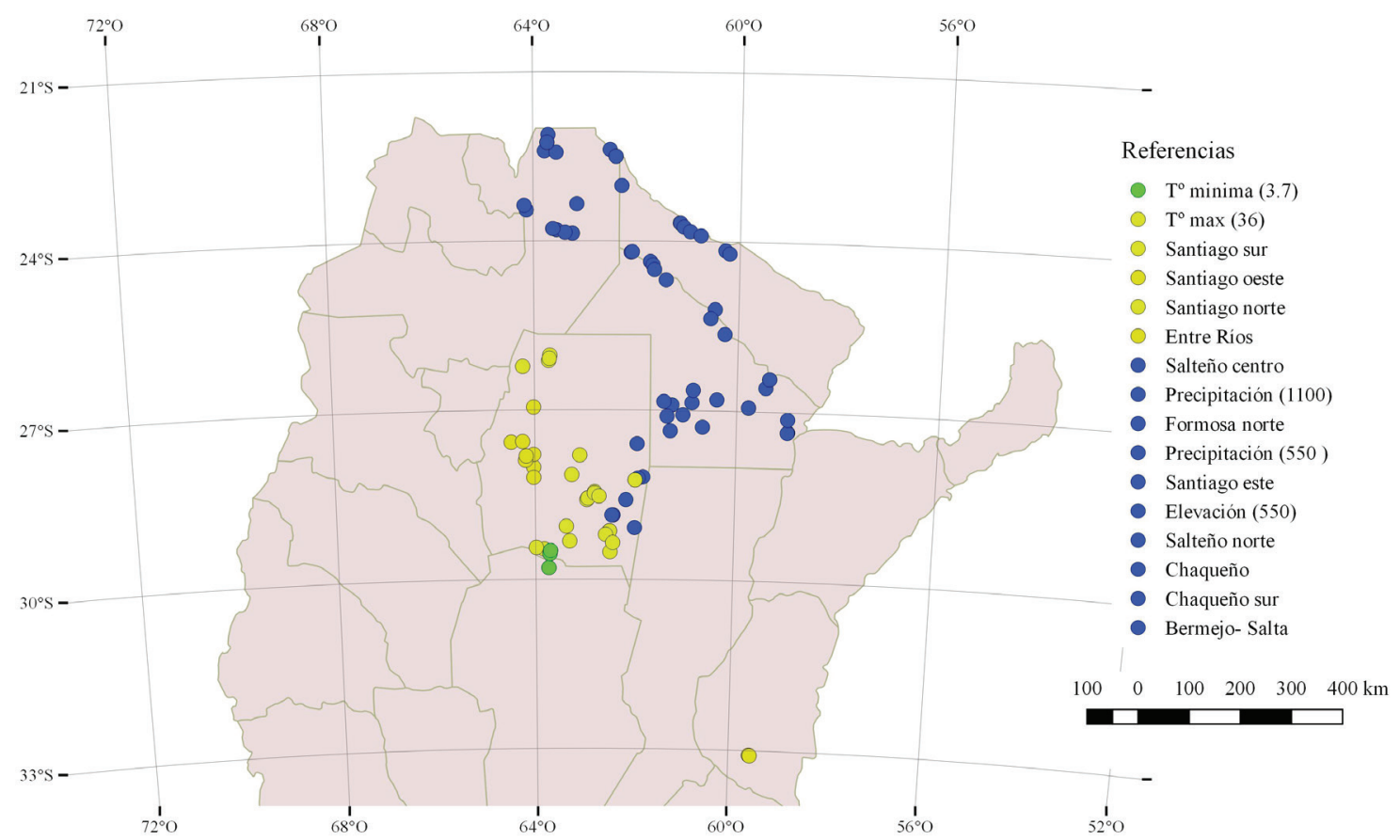

Figura 4. Distribución geográfica de los grupos de brotación formados. En verde el grupo de brotación temprana, en amarillo el grupo de brotación intermedia y en azul el grupo de brotación tardía

de la provincia de Catamarca y oeste de Córdoba. Sus resultados son similares a los de este trabajo en tanto que ambos presentaron una estructura espacial que distingue por índice de brotación el origen geográfico del material utilizado en el ensayo. Si bien las zonas de recolección de Carranza et al. (2000) y la del presente trabajo son diferentes, así como también las especies ( $P$. chilensis vs. P. alba), en ambos casos y dentro de Argentina, los materiales que presentaron índices de brotación más altos fueron el de las poblaciones originarias del oeste y norte de Córdoba.

En cuanto al análisis de componentes principales de siete variables geográficas climáticas, se observa en la Figura 5 que este quedó definido por dos componentes principales que explican el $100 \%$ de la variación observada. Así la componente principal 1 (CP1) explicó un $77,70 \%$ de la variación con una mayor contribución de las variables elevación, latitud, longitud, $\mathrm{T}^{\circ}$ mínima media del mes más frío y $\mathrm{T}^{\circ}$ media anual, mientras que la contribución de la componente principal 2 (CP2) representó un 22,3\%, siendo las variables precipitación y $\mathrm{T}^{\circ}$ máxima media del mes más caliente las más relevantes. En la Figura 5 se observa que la CP1 separa los tres grupos de brotación. Estos resultados concuerdan con los obtenidos por Carranza et al. (2000) para $P$. chilensis que obtuvieron una relación inversa, altamente significativa, entre el índice de brotación con la latitud y longitud; y una relación directa, significativa, entre el índice de brotación y elevación.

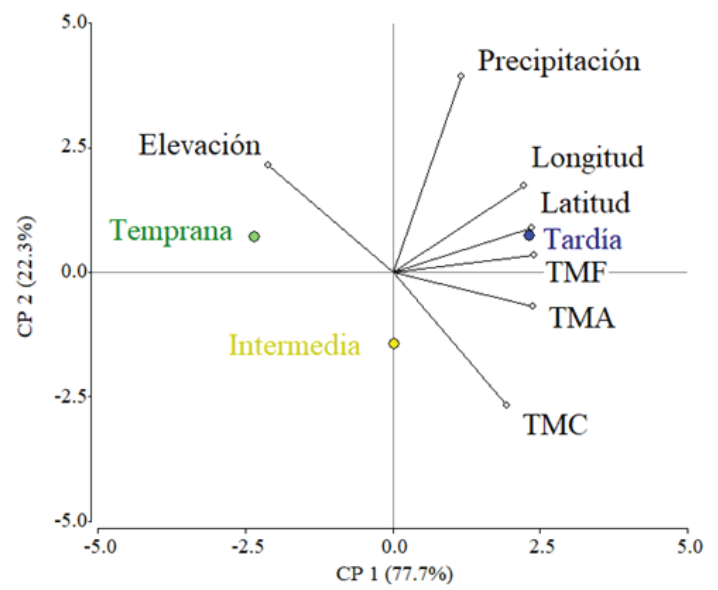

Figura 5. Ordenamiento bidimensional de los grupos de brotación en función de las variables geográfico-climáticas

Existen variables climáticas que caracterizan el origen geográfico de las poblaciones que integran los grupos de brotación $(p<0,05)$ y otras que no $(p>0,05)$. Se destacaron dos variables que lograron separar los tres grupos de brotación: $T^{\circ}$ 
media anual y $T^{\circ}$ mínima media del mes más frío (Tabla 4). Estos resultados muestran que si bien todas las variables que integran el CP1 (altitud, latitud, longitud, $\mathrm{T}^{\circ}$ media anual y $\mathrm{T}^{\circ}$ mínima media del mes más frío) fueron importantes en la definición de los tres grupos, las variables $\mathrm{T}^{\circ}$ media anual y $T^{\circ}$ mínima media del mes más frío fueron las únicas que contribuyeron a diferenciar $(p<0,05)$ entre los tres grupos de brotación, mientras que la $T^{\circ}$ máxima media del mes más caliente separó el grupos de brotación temprana de los restantes grupos, al poseer el grupo de brotación temprana el menor $(p<0,05)$ valor (Tabla 4$)$.

Diversos autores obtuvieron resultados que explican la relación entre temperatura y brotación: Menzel (2003) sostiene que es conocido que existe una fuerte respuesta de las fases fenológicas a la temperatura del aire, principalmente las que ocurren durante la primavera. Ocampo y Orquin (1989), Murphy et al. (1999) y Garau et al. (2000) realizando estudios de brotación de especies nativas y exóticas encontraron que la temperatura fue la que mostró una relación directa con el comienzo de la fase, mientras que la duración de la fase fue inversa. Carnelos et al. (2019) sostienen que el adelanto en el inicio de la fase de brotación observada fue producto del incremento de la temperatura mínima $\left(0,03{ }^{\circ} \mathrm{C}\right.$ por año) registrado desde 1950 al 2018, resultados consistentes con los obtenidos en este trabajo. El grupo de brotación temprana fue el grupo que en el ACP mostró una relación inversa con las variables de temperaturas, y si bien su inicio de brotación es diferencial con respecto a los otros grupos (Figura 3) culmina primero la fase de brotación. El GBTE además se diferencia para las variables de temperaturas con los restantes grupos como lo muestra la Tabla 4. Sin embargo, su comportamiento no puede explicarse a este nivel de estudio basándose en las afirmaciones de los autores mencionados con anterioridad, por no contar con registros de temperatura diarios y anuales medios para la zona del estudio.

Brotación en el tiempo. Los parámetros estimados de la función logística que describe el porcentaje de brotación en función del tiempo, tanto para el conjunto de los individuos evaluados como para cada uno de los grupos de brotación formados, se muestran en la Tabla 5, donde se observan tres funciones específicas de acuerdo al comportamiento de cada uno de los grupos de brotación: temprana, intermedia y tardía.

La Figura 6 muestra las curvas de brotación construidas para cada grupo y que responden a las funciones descriptas en la Tabla 5, así como

Tabla 5. Modelos de porcentaje de brotación en función del tiempo

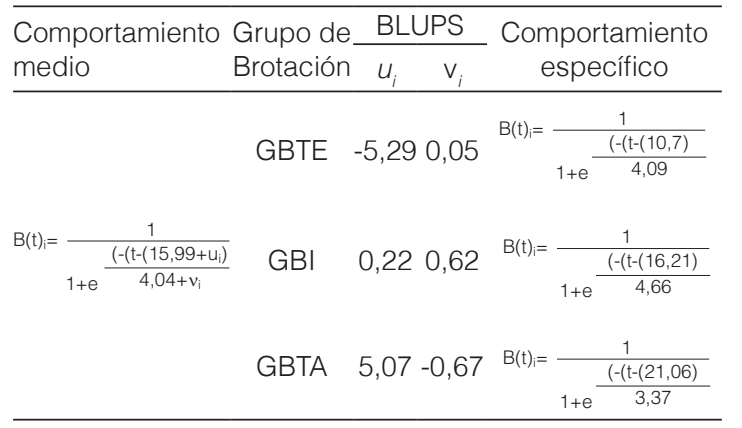

"GBTE: grupo de brotación temprana, GBI: grupo de brotación intermedia y GBTA: grupo de brotación tardía

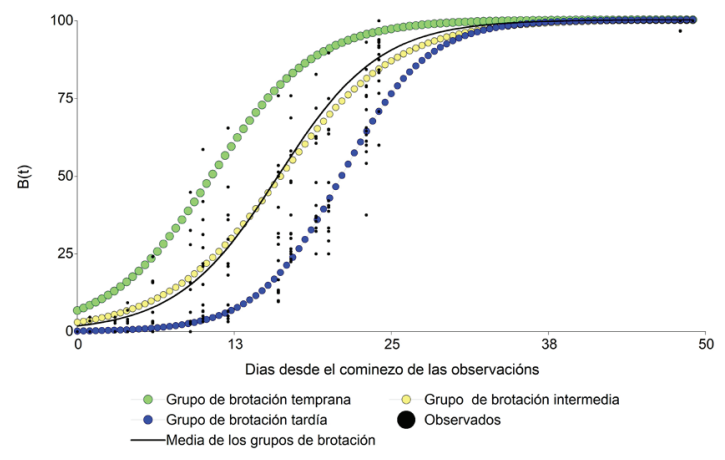

Figura 6. Dinámica temporal de la brotación (\%) para los diferentes grupos de brotación definidos en base a índices de brotación. Curvas obtenidas por un análisis de regresión logística incorporando los grupos de brotación como efectos aleatorios

Tabla 4. Características geográfico-climáticas de los grupos de brotación (GB)

\begin{tabular}{|c|c|c|c|c|c|c|c|c|c|c|c|c|c|c|}
\hline \multirow{2}{*}{$\frac{\mathrm{GB}}{\text { Temprana }}$} & \multicolumn{2}{|c|}{$\operatorname{TMA}^{*}\left({ }^{\circ} \mathrm{C}\right)$} & \multicolumn{2}{|l|}{$\begin{array}{l}\text { TMF }^{*} \\
\left({ }^{\circ} \mathrm{C}\right)\end{array}$} & \multicolumn{2}{|l|}{$\begin{array}{l}\text { TMC }^{*} \\
\left({ }^{\circ} \mathrm{C}\right)\end{array}$} & \multicolumn{2}{|c|}{$\begin{array}{l}\text { Elevación } \\
\text { (m.s.n.m.) }\end{array}$} & \multicolumn{2}{|c|}{$\begin{array}{l}\text { Precipitación } \\
\text { (mm) }\end{array}$} & \multirow{2}{*}{$\begin{array}{c}\begin{array}{c}\text { Longitud } \\
\text { (grados) }\end{array} \\
-63,71\end{array}$} & \multicolumn{3}{|c|}{$\begin{array}{l}\text { Latitud } \\
\text { (grados) }\end{array}$} \\
\hline & 17,80 & $\mathrm{C}$ & 3,36 & $C$ & 31,63 & $B$ & 556 & $A$ & 761 & $A$ & & B & $-29,61$ & $B$ \\
\hline EE & 0,584 & & 0,675 & & 0,661 & & 75,27 & & 95,22 & & 0,77 & & 1,10 & \\
\hline Intermedia & 20,48 & B & 5,76 & $B$ & 34,90 & $A$ & 191 & $B$ & 670 & B & $-63,44$ & B & $-28,22$ & B \\
\hline EE & 0,171 & & 0,198 & & 0,193 & & 22,04 & & 27,88 & & 0,23 & & 0,32 & \\
\hline Tardía & 21,95 & $A$ & 8,79 & $A$ & 34,47 & $A$ & 181 & B & 848 & A & $-61,69$ & A & $-25,53$ & $\pi$ \\
\hline EE & 0,128 & & 0,148 & & 0,145 & & 16,56 & & 20,95 & & 0,17 & & 0,24 & \\
\hline
\end{tabular}

Medias con una letra común no son significativamente diferentes $(p>0,05)$. 'TMA: $T^{\circ}$ media anual, TMF: $T^{\circ}$ mínima media del mes más frío y TMC: $T^{\circ}$ máxima media del mes más caliente. 
también el comportamiento medio de los grupos de brotación, que posee un comportamiento similar al grupo de brotación intermedia.

Velocidad media de crecimiento de los brotes (VMCB). No se encontraron diferencias significativas $(p>0,05)$ entre longitud del brote en función del DAP, por lo que para el cálculo de la velocidad media de crecimiento no se tuvieron en cuenta los DAP de los árboles medidos. Resultados similares se obtuvieron entre la orientación de los brotes marcados (norte, sur, este y oeste) en la variable longitud del brote donde tampoco se obtuvieron diferencias significativas $(p>0,05)$, por lo que la variable utilizada para la construcción de la velocidad media de crecimiento de los brotes fue un promedio de las cuatro orientaciones.

La velocidad media de crecimiento de los brotes tuvo un comportamiento diferencial según el origen geográfico-climático $(p<0,05)$ dando lugar a la formación de dos grupos, unos de mayor velocidad y otro de menor velocidad (Tabla 6), denominados en este estudio grupo de velocidad media de crecimiento de los brotes rápido (GVMCBRa) y grupo de velocidad media de crecimiento de los brotes lento (GVMCBLe). Carranza et al. (2000) en su ensayo genecológico de $P$. chilensis (ut supra) no encontraron diferencias entre los crecimientos de brotes de las distintas procedencias.

Con respecto al crecimiento de los brotes de Prosopis, Sharif et al. (1983) lo describen como rápido, pero de corta duración, y puntualmente analiza el comportamiento de P. glandulosa Torr. en California para dos temporadas de crecimiento.
En la primera, de febrero a noviembre de 1980 registraron un crecimiento medio de los brotes de $23,4 \mathrm{~cm}$, mientras que en la segunda temporada, de julio a diciembre, el crecimiento fue de $25,8 \mathrm{~cm}$, lo que sería igual a un crecimiento diario de 0,078 y $0,14 \mathrm{~cm} /$ día respectivamente, valores más bajos que los obtenidos en Santiago del Estero para $P$. alba (crecimiento mínimo $=0,28 \mathrm{~cm} /$ día, crecimiento máximo $=0,44 \mathrm{~cm} /$ día).

Los dos grupos formados mostraron un ordenamiento espacial, tal como se muestra en la Figura 7, donde se observa que los orígenes Salteño centro, Chaqueño sur, Bermejo-salta y Chaqueño quedan agrupados en el centro de las familias analizadas, y las restantes 12 familias se ubican rodeando a estas en orientación norte, sur y este. Sin embargo, no se observó una autocorrelación espacial de la velocidad media de crecimiento de los brotes (índice de Moran =0,11- $p<0,05$ ).

Las variables que registraron una diferencia entre grupos de velocidad media de crecimiento de los brotes rápida y grupo de velocidad media de crecimiento de los brotes lento fueron $\mathrm{T}^{\circ}$ media anual, $T^{\circ}$ mínima media del mes más frío y latitud, confirmados por un ANAVA $(p<0,05)$ y test de comparación de medias DGC (Tabla 7).

Sharif et al. (1983) realizan correlaciones entre variables ambientales de las dos temporadas de crecimiento y el evento fenológico descripto (crecimiento de los brotes), para lo cual describen que el primer crecimiento se produjo durante bajas temperaturas (máxima $20{ }^{\circ} \mathrm{C}$ ) y alta humedad de suelo (9\%), y el segundo crecimiento se produjo con

Tabla 6. Velocidades medias de crecimiento de los brotes (VMCB) por orígenes geográfico-climáticos

\begin{tabular}{lcccc}
\hline Orígenes geográfico-climáticos & VMCB (cm/día) & E.E. & & Grupo de VMCB* \\
\hline Salteño centro & 0,44 & 0,05 & A & \\
Chaqueño sur & 0,44 & 0,03 & A & Rápido (GVMCBRa) \\
Bermejo- salta & 0,44 & 0,05 & A & \\
Chaqueño & 0,40 & 0,03 & A & \\
Formosa norte & 0,37 & 0,04 & B & \\
T'max (36) & 0,37 & 0,03 & B & \\
Precipitación (1100) & 0,36 & 0,03 & B & \\
Precipitación (550) & 0,34 & 0,04 & B & \\
Santiago sur & 0,34 & 0,03 & B & \\
Elevación (550) & 0,34 & 0,02 & B & Lento (GVMCBLe) \\
Santiago oeste & 0,34 & 0,03 & B & \\
T' mínima (3,7) & 0,33 & 0,02 & B & \\
Santiago este & 0,33 & 0,03 & B & \\
Salteño norte & 0,31 & 0,05 & B & \\
Entre Ríos & 0,28 & 0,03 & B & \\
Santiago norte & 0,28 & 0,03 & B & \\
\hline
\end{tabular}

Medias con una letra común no son significativamente diferentes ( $p>0,05)$. VMCB: velocidad media de crecimiento de los brotes, GVMCBRa: grupo de velocidad media de crecimiento de los brotes rápido y GVMCBLe: grupo de velocidad media de crecimiento de los brotes lento 


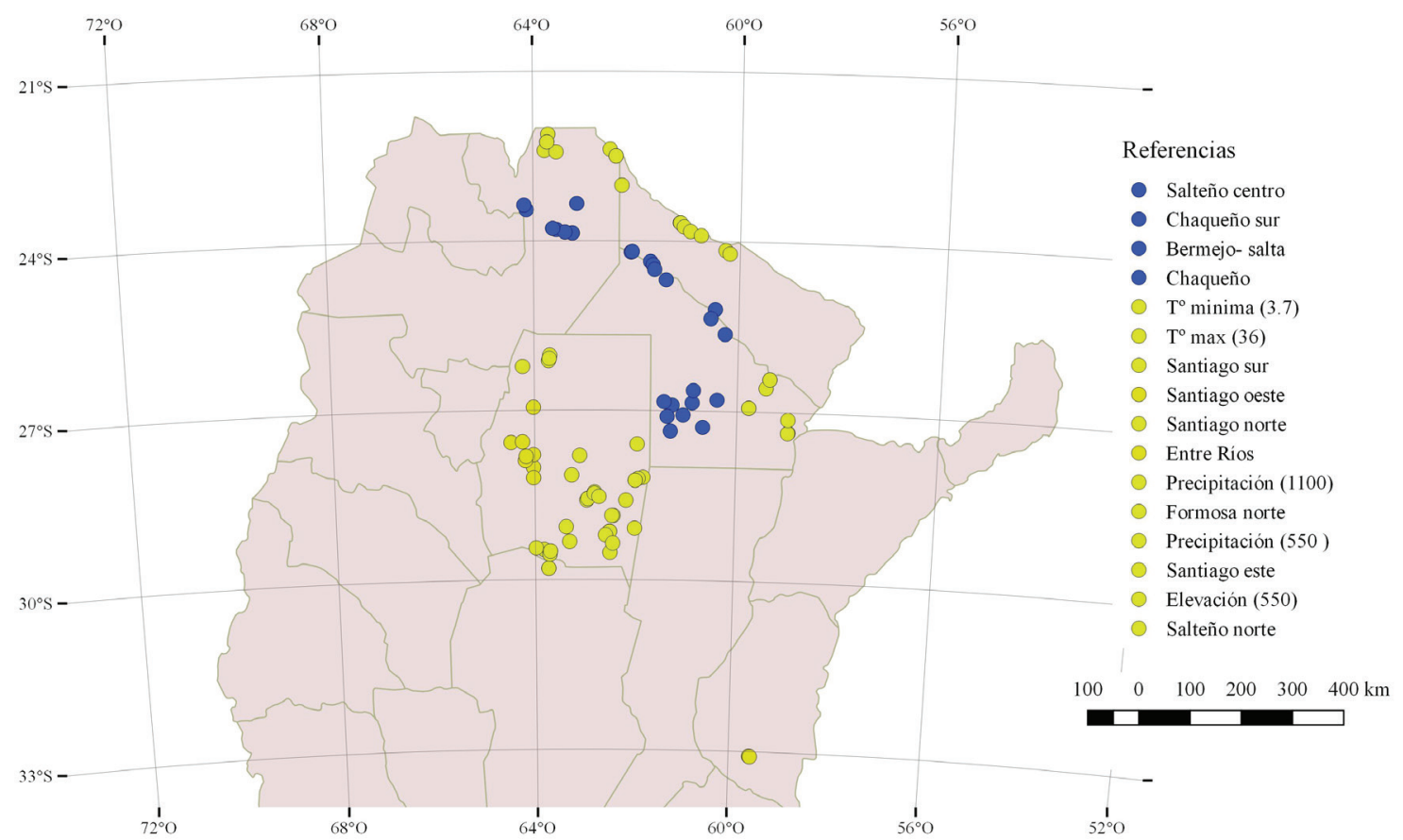

Figura 7. Distribución geográfica de los grupos formados para velocidad media de crecimiento de los brotes

altas temperaturas (máxima $45^{\circ} \mathrm{C}$ ) y baja humedad de suelo (5\%). Los resultados del presente trabajo muestran que las correlaciones entre estas dos variables fueron mínimas, aunque relaciona el mayor crecimiento de la segunda temporada a las altas temperaturas que hubo en ese período.

\section{Análisis integral de las variables estudiadas}

Es de destacar que hubo un comportamiento diferencial de los orígenes geográfico-climáticos, formados a partir de 88 familias de polinización abierta, al observar el índice de brotación y la velocidad media de crecimiento de los brotes. Tal como se muestra en la Figura 8 , hubo un grupo de familias que brotaron primero (índice de brotación temprana) pero con velocidad media de crecimiento de los brotes lenta, como el OGC T mínima 3,7; otro grupo que presentó brotación tardía (índice de brotación tardía) pero con velocidad media de crecimiento de los brotes rápida como los orígenes Bermejo Salta, Salteño centro, Chaqueño y Chaqueño sur; un tercer grupo que presentó un índice de brotación intermedia y velocidad media de crecimiento de los brotes lenta como lo son los orígenes geográfico-climáticos Santiago norte, Santiago sur, Santiago oeste, Entre

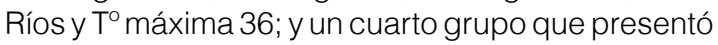
índice de brotación tardío y velocidad media de crecimiento de los brotes lenta conformada por los orígenes Salteño norte, Formosa N, Elevación (550), Precipitación (1100), Precipitación (550) y Santiago este. No se encontraron estrategias de brotación conformadas por índice de brotación intermedio con velocidades de crecimiento de

Tabla 7. Características geográfico-climáticas de los grupos de velocidad media de crecimiento de los brotes (VMCB)

\begin{tabular}{|c|c|c|c|c|c|c|c|c|c|c|c|c|c|c|}
\hline \multirow{2}{*}{$\begin{array}{l}\text { Grupo de } \\
\text { VMCB }^{*} \\
\text { GVMCBRa }\end{array}$} & \multicolumn{2}{|c|}{$\begin{array}{l}\mathrm{TMA}^{* *} \\
\left({ }^{\circ} \mathrm{C}\right)\end{array}$} & \multicolumn{2}{|c|}{$\begin{array}{l}\mathrm{TMF}^{* *} \\
\left({ }^{\circ} \mathrm{C}\right)\end{array}$} & \multicolumn{2}{|c|}{$\begin{array}{c}\text { TMC } \\
\left({ }^{\circ} \mathrm{C}\right)\end{array}$} & \multicolumn{2}{|c|}{$\begin{array}{l}\text { Elevación } \\
\text { (m.s.n.m.) }\end{array}$} & \multicolumn{2}{|c|}{$\begin{array}{l}\text { Precipitación } \\
(\mathrm{mm})\end{array}$} & \multicolumn{2}{|c|}{$\begin{array}{l}\text { Longitud } \\
\text { (grados) }\end{array}$} & \multicolumn{2}{|c|}{$\begin{array}{l}\text { Latitud } \\
\text { (grados) }\end{array}$} \\
\hline & 22,30 & $A$ & 9,03 & $A$ & 34,79 & $A$ & 207,59 & $A$ & 834,43 & $A$ & $-61,88$ & $A$ & $-25,21$ & $A$ \\
\hline EE & 2,37 & & 3,28 & & 2,26 & & 17,15 & & 32,15 & & 0,27 & & 0,43 & \\
\hline GVMCBLe & 20,90 & $B$ & 7,03 & $\mathrm{~B}$ & 34,41 & $A$ & 166,03 & A & 768,13 & $A$ & $-62,51$ & $A$ & $-27,12$ & $B$ \\
\hline EE & 1,55 & & 2,15 & & 1,48 & & 26,19 & & 21,04 & & 0,18 & & 0,28 & \\
\hline
\end{tabular}

Medias con una letra común no son significativamente diferentes ( $p>0,05)$. $G$ GMCBRa: grupos de velocidad media de crecimiento de Ios brotes rápida y GVMCBLe: grupo de velocidad media de crecimiento de los brotes lento "TMA: T media anual, TMF: T mínima media del mes más frío y TMC: $T^{\circ}$ máxima media del mes más caliente 
brotes rápidas, ni por índice de brotación temprana con velocidad media de crecimiento de los brotes rápida.

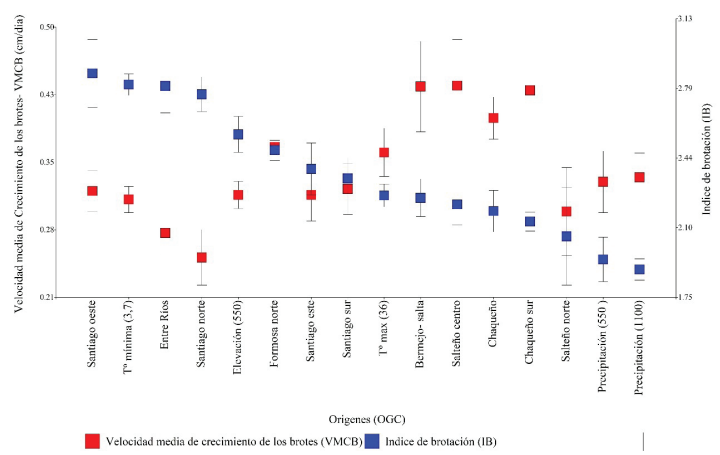

Figura 8. Diagrama de dispersión de índice de brotación y velocidad media de crecimiento de los brotes en función de los orígenes geográfico-climáticos (OGC)

Los grupos de brotación (temprana, intermedia y tardía) y los grupos de velocidad media de crecimiento de los brotes (rápida y lenta) presentaron una distribución espacial diferente. Las variables asociadas a esa diferenciación para ambos casos fueron las $T^{\circ}$ media anual y $T^{\circ}$ mínima media del mes más frío. Esta coincidencia podría estar influenciando el comportamiento diferencial en cuatro grupos de estrategia de brotación. Puede observarse la distribución espacial de los cuatro grupos de brotación en la Figura 9.

\section{CONCLUSIONES}

Sobre la base de los resultados se concluye que existen diferentes estrategias de brotación en las 88 familias de polinización abierta de $P$. alba introducidas en el ensayo de origen de Santa María en Santiago del Estero. Esta variación se diferencia en tres grupos de brotación y dos grupos de velocidad de brotación, y de la combinación de estas variables surgen cuatro grupos de estrategia de brotación.

Se evidencia la existencia de una estructura espacial diferencial tanto para los grupos de brotación (temprana, intermedia y tardía) como para los grupos de velocidad media de crecimiento de los brotes (rápida y lenta).

Existe un patrón que relaciona los grupos de brotación con los grupos de velocidad media de crecimiento de los brotes, donde todos los orígenes que conforman el grupo de velocidad media de

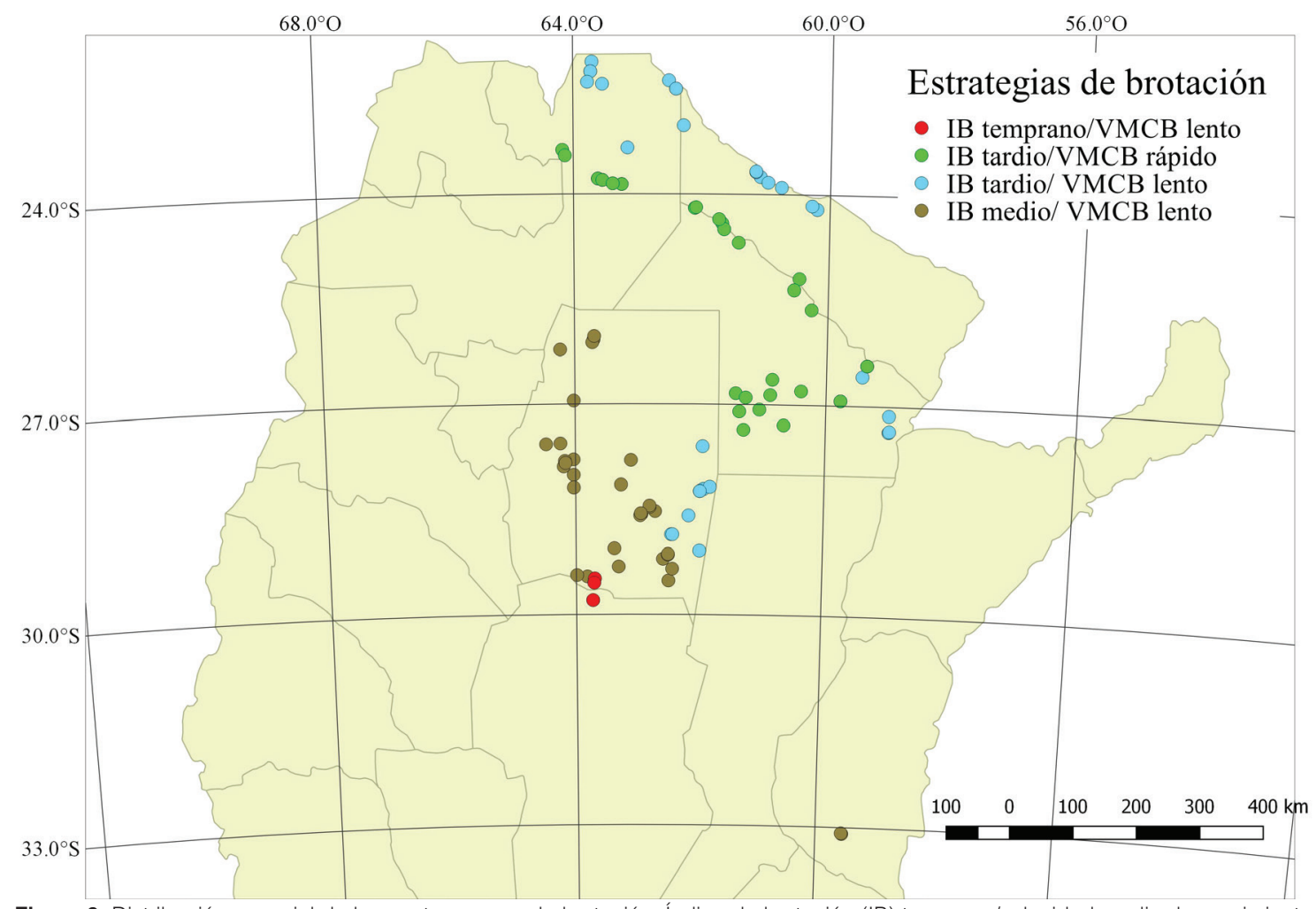

Figura 9. Distribución espacial de los cuatro grupos de brotación. Índice de brotación (IB) temprano/velocidad media de crecimiento de los brotes (VMCB) lenta, IB tardío/ VMCB rápido, IB tardío/ VMCB lento, IB medio/ VMCB lento 
crecimiento de los brotes rápida se encuentran dentro del grupo de brotación tardía.

Las temperaturas medias anual y del mes más frío diferencian los grupos de brotación y los de velocidad media de crecimiento de los brotes.

A partir de estas conclusiones se sugiere que en caso de transferencia de materiales genéticos de $P$. alba de un lugar a otro se considere la estrategia de brotación (combinación del grupo de brotación y grupo de velocidad media de crecimiento del brote) a la cual pertenece la población. Respetando esta sugerencia la planta brotará en un período en el que ya no existe riesgo de daño por evento geográfico-climático no óptimo para la población.

\section{AGRADECIMIENTOS}

A la Dra. Juana Moglia, a los Ing. Felipe Cisneros, Fanny Coronel, Guillermo Clausen y al Lic. Fernando Chaves por su predisposición y valiosos aportes.

A los directores del Instituto Nacional de Tecnología Agropecuaria (INTA) y del Proyecto PICTO No 1/18608 (Evaluación de la variación genética de especies del género Prosopis de la Región Chaqueña argentina para su conservación y mejoramiento) por permitir el uso del ensayo como material base para este estudio.

Los fondos para este trabajo fueron aportados por el Banco Nacional de Germoplasma de Prosopis y la Secretaría de Ciencia y Tecnología de la Universidad Nacional de Córdoba.

\section{BIBLIOGRAFÍA}

Carnelos, D., Zapiola, G. M. F., Peretti, M. y Fernández Long, M. E. (2019). Modificaciones del comportamiento fenológico de algunas especies forestales como consecuencia de cambios en el clima de la ciudad de Buenos Aires (Argentina). Agronomía \& Ambiente, 39 (2).

Carranza, C., Verzino, G., Di Rienzo, J., Ledesma M. y Joseau, J. (2000). Componentes de la variación adaptativa en Prosopis chilensis: el índice de brotación. Multequina9, 55-64.

Córdoba, A. y Verga, A. (2008). Método de análisis fenológico de un rodal: Su aplicación en un enjambre híbrido de Prosopis spp. Revista ciencia e investigación forestal, 14, 91-109.

Coronel de Renolfi, M., Díaz F. y Cardona, G. (2012). Rendimientos, productividad y costos del aserrado primario de algarrobo blanco (Prosopis alba) en Santiago del Estero. En: G. Verzino, M. J. Joseau y R.
Coirini (Eds.), Reunión Nacional del Algarrobo Actas (pp. 40-42). Córdoba, Argentina: Encuentro Grupo Editor.

de Galindez, M. J., Giménez, A. M., Ríos, N. y Balzarini, M. (2005). Modelación de crecimiento en Prosopis alba Griseb. empleando dos modelos biológicos. Quebracho-Revista de Ciencias Forestales, 12, 34-42.

Debandi, G., Rossi, B. E., Villagra, P. E., Giantomasi, M. A. y Mantován, N. G. (2020). Spatial and temporal synchronicity in the phenological events of Prosopis flexuosa in the Central Monte Desert. Revista de la Facultad de Ciencias Agrarias UNCuyo, 52, 148-160.

Dietrichson, J. (1964). The selection problem and growth rhythm. Silvae Genetica, 13, 178-184.

Di Rienzo, J. A., Casanoves, F., Balzarini, M. G., Gonzalez, L., Tablada, M. y Robledo C. W. InfoStat (versión 2018) [Software]. Córdoba, Argentina: Grupo InfoStat, FCA, Universidad Nacional de Córdoba. http://www.infostat. com.ar

Fontana, M. L., Pérez, V. R. y Luna, C. V. (2020). Efecto de la procedencia sobre el comportamiento productivo de Prosopis alba en plantación. Acta Agronómica, 69, 68-74. https://doi.org/10.15446/acag.v69n1.79711

Frassoni, J. E. y Joseau, M. J. (2019). Development of a height estimation method based on the diameter at breast height of Prosopis alba Grisebach selected populations from a progeny trial in Santiago del Estero, Argentina. Agriscientia, 36(2), 89-95. https://doi. org/10.31047/1668.298x.v36.n2.24310

Galera, F. M. (2000). Los algarrobos: las especies del género Prosopis (algarrobos) de América Latina con especial énfasis en aquellas de interés económico. Graziani gráfica.

Garau, A., Filippini de Delfino, S. y Berrondo, G. (2000). Influencia de factores climáticos en las fechas de inicio de floración y brotación de clones de álamo en el delta del Paraná, Argentina. Investigación agraria. Sistemas y recursos forestales, 9, 169-176.

Joseau, M. J., Verga, A. R., Díaz, M. del P. y Julio, N. B. (2013). Morphological diversity of populations of the genus Prosopis in the Semiarid Chaco of northern Cordoba and southern Santiago del Estero. American Journal of Plant Sciences, 4(11), 2092-2111. https:/l doi.org/10.4236/ajps.2013.411261

Joyce, D., Nitschke, P. y Mosseler, A., (2001). Genetic resource management. En R. G. Wagner y S. J. Colombo (Eds), Regenerating the canadian forest: Principles and Practice for Ontario (141-156). Fitzhenry and Whiteside Limited.

Karlin, M. S., Karlin, U. O., Coirini, R. O., Reati, G. J. y Zapata, R. M. (2013). El chaco árido. Encuentro Grupo Editor.

Ledesma, T., De Bedia, G. y López, C. (2008). Productividad de Prosopis alba Griseb en Santiago 
del Estero. Quebracho-Revista de Ciencias Forestales, 15, 5-8.

Levins, R. (2020). Evolution in changing environments: some theoretical explorations (MPB-2) (Vol. 94). Princeton University Press.

López, C., Maldonado, A. y Salim, V. (2001). Variación genética de progenies de Prosopis alba. Forest Systems, 10, 59-68.

López Lauenstein, D., Teich, I., Carloni, E., Melchiorre, M., Sagadin, M., Frassoni, J. y Joseau, M. J. (2021) Genetic Breeding of Prosopis Species from the "Great American Chaco". En: Pastorino M.J., Marchelli P. (Eds.) Low Intensity Breeding of Native Forest Trees in Argentina (271-293). Springer, Cham. https://doi. org/10.1007/978-3-030-56462-9_10

López Lauenstein, D., Vega, C.; Luna, C., Sagadin, M., Melchiorre, M., Pozzi, E., Salto, C., Oberschelp, J., Torales, S., Pomponio, F., Kees, S., Chávez Díaz, L., Gomez, C. y Verga, A. (2016). Subprograma Prosopis. Domesticación y mejoramiento de especies forestales (113-136). Ciudad Autónoma de Buenos Aires, Argentina. Unidad para el Cambio Rural, INTA. http:// forestoindustria.magyp.gob.ar/archivos/bibliotecaforestal/domesticacion-y-mejoramiento-de-especiesforestales.pdf

Menzel, A. (2003). Plant phenological anomalies in Germany and their relation to air and NAO. Climatic Change, 57(3), 243-263.

Murphy, G. M., Sierra, E. M. y Pérez, S. P. (1999). Variación de la temperatura máxima diaria primaveral en un espacio verde de la ciudad de Buenos Aires y su relación con la brotación de las plantas. Revista Facultad de Agronomía, 19(3), 285-290.

Navall, M., Ewens, M., Senilliani, G. y López, C. (2015). Efectos de la poda en plantaciones jóvenes de Prosopis alba Griseb. en Santiago del Estero, Argentina. Quebracho-Revista de Ciencias Forestales, 23(2), 77-91.

Ocampo, E. N. y Orquin, L. E., (1989). Aspectos fenológicos de 19 especies del bosque de caldén y sus posibles relaciones con la temperatura y las precipitaciones pluviales. Revista de la Facultad de Agronomía, Universidad Nacional de La Plata. 65(12), 5-12.

Pachauri, R. K. y Reisinger, A. (2007). Cambio climático 2007: Informe de sintesis. Contribución de los Grupos de trabajo I, II y III al Cuarto Informe de evaluación del Grupo Intergubernamental de Expertos sobre el Cambio Climático (IPCC, por sus siglas en inglés). Grupo Intergubernamental de Expertos sobre el Cambio Climático. https://www.ipcc.ch/site/assets/ uploads/2018/02/ar4 syr sp.pdf
Parizek, B., De La Reta, M., Catalán, L., Balzarini, M. y Karlin, U. (2000). Observaciones fenológicas del algarrobo negro (Prosopis flexuosa D.C.) y del algarrobo blanco (Prosopis chilensis (Mol.) Stuntz) en el Chaco Árido, Argentina. Multequina, 9, 135-146.

QGIS geographic information system (2016) [Software]. QGIS Development Team, Open source geospatial Foundation.

Rehfeldt, J. (1984). Microevolution of conifers in the northern Rocky Mountains: a view from common gardens. En Eighth North American Forest Biology Workshop (132-146), Logan, Utah, Estados Unidos: Utah State University.

Salto, C. S. (2011). Variación genética en progenies de polinización abierta de Prosopis alba Griseb. de la región chaqueña. Tesis de Maestría. Universidad Nacional de Rosario, Argentina.

Salto, C. S., Harrand, L., Oberschelp, J. y Ewens, M. (2019). Efecto del tamaño de envase y calidad del sustrato utilizado sobre la calidad del plantín de Prosopis alba. En C. S. Salto, A. M. Lupi (Eds.), Avances en el conocimiento y tecnologías productivas de especies arbóreas nativas de Argentina (12-15). Ediciones INTA.

Sharifi, M. R., Nilsen, E. T., Virginia, R., Rundel, P. W. y Jarrell, W. M. (1983). Phenological patterns of current season shoots of Prosopis glandulosa var. torreyana in the Sonoran Desert of southern California. Flora, 173(3-4), 265-277.

Secretaria de Agricultura, Ganadería y Pesca [SAGyP] e Instituto Nacional de Tecnología Agropecuarias [INTA] (2013). Proyecto PNUD ARG/85/019. (Versión 9.0). http://www.geointa.inta.gob.ar/2013/05/26/suelos-dela-republica-argentina/

Spano, D., Cesaraccio, C., Duce, P. y Snyder, R. L. (1999). Phenological stages of natural species and their use as climate indicators. International Journal of Biometeorology, 42, 124-133. https://doi.org/10.1007/ $\underline{\mathrm{s} 004840050095}$

Verzino, G. y Joseau, M. J. (2005). El Banco Nacional de Germoplasma de Prosopis: conservación de recursos forestales nativos en Argentina. Facultad de Ciencias Agropecuarias, Universidad Nacional de Córdoba.

Verga, A., López Lauenstein, D. L., López, C., Navall, M., Joseau, J., Gómez, C., Royo, O., Degano W., y Marcó, M. (2009). Caracterización morfológica de los algarrobos (Prosopis sp.) en las regiones fitogeográficas Chaqueña y Espinal norte de Argentina. Quebracho-Revista de Ciencias Forestales, 17(1-2), 31-40. 